\title{
Evaluation of Ocimum suave essential oil against anthropophilic malaria vector Anopheles gambiae s.s after ten years of storage
}

\author{
E.J.KWEKA ${ }^{1 *}$, B. J. MWANG'ONDE ${ }^{1}$, M.J.MAHANDE², F.W.MOSHA ${ }^{2}$, E. E. KIMARO', S. MSANGI ${ }^{1}$, L. \\ LYARUU $^{1}$ and A. M. MAHANDE ${ }^{3}$ \\ ${ }^{1}$ Tropical Pesticides Research Institute, P.O. Box 3024, Arusha, Tanzania \\ ${ }^{2}$ Kilimanjaro Christian Medical College of Tumaini University, Moshi, Tanzania \\ ${ }^{3}$ Tropical Pesticides Research Institute, Mabogini Field Station, Moshi, Tanzania
}

\begin{abstract}
Interruption of vector-human contact is of priority in breaking the transmission chain of malaria parasites. The use of plant extracts as repellents against malaria vectors have been advocated in different studies. The objective of this study was to evaluate the protective efficacy of freshly distilled and ten years old essential oil of Ocimum suave against Anopheles gambiae s.s. The feeding inhibition of old and freshly prepared O. suave extracts in liquid paraffin or glycerine were compared with $\mathrm{N}, \mathrm{N}$-diethyl-3-methylbenzamide (DEET) using mosquito cage evaluation. There was no significant difference between the ten years stored and freshly prepared $O$. suave extract in either glycerine $(\mathrm{t}=0.578, \mathrm{df}=58, P=0.566)$ or liquid paraffin $(\mathrm{t}=0.148, \mathrm{df}=58$, $P=0.883)$. Neither ten years old $(P=0.423$ in glycerine and $P=0.423$ in liquid paraffin) or freshly prepared ( $P=0.427$ in glycerine and $P=0.412$ in liquid paraffin) $O$. suave extracts had significant difference against DEET in protection efficacy. Comparison of the mean between $O$. suave in glycerine and in paraffin had no difference $(\mathrm{t}=1.445, \mathrm{df}=24, P=0.161)$. Therefore, promotion of plant extracts for commercialization is of priority in rural Tanzania where whole plants are currently used as repellents against malaria vectors.
\end{abstract}

Keywords: Repellents, Anopheles gambiae, Ocimum suave, feeding inhibition, Tanzania

There have been efforts to promote plant-based repellents for community use against malaria vectors and other nuisance biting insects. In most communities there are resourceful plants which have shown some repellent properties and have been used traditionally to protect against insects of medical and veterinary importance (Pålsson \& Jaenson, 1999). Several plant species have been used against malaria vectors as repellents (Waka et al., 2004). The major drawback reported has been on the longevity of active ingredients of the plant extracts if not properly stored (Wells et al., 1993).

Most of the active compounds of the plant materials do degrade upon exposure to bright sunlight and high temperatures. Volatility of the essential oils has been another factor to be monitored in these plants extracts (Wells et al., 1993). In addition, the compounds might undergo chemical reaction with ingredients of some of the solvents used to make oil for skin application. The use of proper solvents, storage in dark and cool places might increase their longevity and thus provide an appropriate alternative tool to supplement the existing control methods against haematophagus insects (Omolo et al., 2004; Odalo et al., 2005).

The essential oils of Ocimum suave plants have shown a significance impact in repellence and feeding inhibition both in the field and laboratory against malaria vectors and other nuisance insects (Kweka et al., 2008; Omolo et al., 2004; Odalo et al., 2005). However, uncertainties have been expressed on the shelf life and viability of the efficacy of active ingredients of essential oils from plant extracts, following long term storage. Therefore, it was the objective of this study to evaluate the protective efficacy of freshly distilled and ten years old essential oil of O. suave against An. gambiae sensu stricto.

The ten years old essential oils were distilled from $O$. suave plant leaves at the International Centre for Insect Physiology and Ecology, Nairobi, Kenya in 1998. The essential oil was collected in a sealed bottle wrapped with black material and stored in a dark wardrobe cabin for ten years at $18^{\circ} \mathrm{C}$ to $20^{\circ} \mathrm{C}$. The fresh essential oil was distilled at the Tropical Pesticide Research Institute(TPRI), Arusha, Tanzania from the $O$. suave plant materials collected around TPRI in 2008. The freshly prepared and ten years old $O$. suave essential oils were compounded with two different materials; liquid paraffin and glycerine (in volumes ratios). DEET was used as positive control in both experiments.

Liquid paraffin was used to make up the first mixture with essential oils to be applied on human skin. The mixture was made up in 2 parts of essential oil and 8 parts of liquid paraffin 
$(\mathrm{v} / \mathrm{v})$, the mixture was miscible. Glycerine was used to make up the second mixture that was applied on human skin (containing 2 parts of essential oils and 8 parts (v/v) of glycerine), the mixture was partially miscible. Humans were used as study subjects during this study.

All laboratory tests were conducted using female malaria-free An. gambiae s.s (Kisumu strain) from the Tropical Pesticides Research Institute insectary. The colony was maintained in insectary conditions of $27 \pm 2^{\circ} \mathrm{C}$, $75-85 \%$ relative humidity and 12:12 (light / dark) photoperiod. Adults of 2-3 days old mated female mosquitoes that were only provided with a sugar meal were used in the assays to determine feeding inhibition by extracts of $O$. suave.

Two sets of experiments were carried out. In the first, 50 mosquitoes were used per replicate while in the second phase 100 mosquitoes were used. Two volunteers, a female (34years) and a male (35 years) were used for the experiments. The person volunteered to feed mosquitoes wore a short-sleeve shirt to allow maximum access of the arm by the mosquitoes. To determine feeding inhibition, human volunteer arms, were inserted in a cage for one hour, each arm with equal numbers of unfed female mosquitoes (50 or 100). One arm was treated with mixture of glycerine and $O$. suave essential oils while the other arm was treated with glycerine alone (control). In another experiment, one arm was treated with mixture of liquid paraffin and $O$. suave essential oils while the other arm of the same person was treated with liquid paraffin alone (control). The positive control was DEET. All formulations were evaluated in a cage of $30 \mathrm{~cm} \times 30 \mathrm{~cm} \times 30 \mathrm{~cm}$. Each experiment had five replicates for every treatment. Comparison of the arm treated with plant essential oils and DEET in glycerine or liquid paraffin with 50 and 100 mosquitoes were done in the same size cages. Before the beginning of the study, informed consent, both oral and written where obtained from the volunteers. Ethical clearance was obtained from Kilimanjaro Christian Medical Centre Research Ethics Committee.

Data were entered twice for validation in MS-Excel in order to cross check for data entry errors. Data were then analyzed using SPSS version 15 for windows. The repellency, expressed as protective efficacy (PE) at each treatment was calculated from five replicates using the formula by Merh et al. (1985):

$P E=[($ mosquitoesfed in control - Mosquitoes fed in test)/mosquitoes fed in control mean]

A paired sample t-test assuming equal variance (homoscedastic) was used to estimate the comparisons of the means between the percentage protection efficiency in fresh and ten years old $O$. suave extracts against standard repellent (DEET). Significant level was considered when alpha was less than 5\%.

A total of 60 replicates were done in each experiment. For all three samples evaluated (fresh $O$. suave, ten years old $O$. suave and DEET) the feed inhibition ranged from $88.7 \%$ to $96.8 \%$. The comparison of the feeding inhibition between fresh and ten years old essential oil in glycerine was not statistically different $(\mathrm{t}=$ 0.578 , df $=58, P=0.566)$. Similarly, there was no significance difference in feeding inhibition between fresh and ten years old essential oil in liquid paraffin ( $\mathrm{t}=0.148, \mathrm{df}=58, P=0.833$ ). There was no difference between solvents used (glycerine and liquid paraffin) $(\mathrm{t}=1.445, \mathrm{df}=$ $24, P=0.161)$. The feeding inhibition was not significantly different between the ten years old or fresh O. suave and DEET (standard repellent) (Table 1).

Table 1: The feeding inhibition and repellence efficiency of $O$. suave and DEET against An. gambiae s.s

\begin{tabular}{|c|c|c|c|c|c|c|}
\hline $\begin{array}{l}\text { Combination } \\
\text { evaluated }\end{array}$ & $\begin{array}{l}\text { No. of mosquito } \\
\text { per replicate }\end{array}$ & Total tested & No. fed & $\begin{array}{l}\% \\
\text { Protection } \\
\text { efficiency }\end{array}$ & P-value & Mean $(95 \% \mathrm{CI})$ \\
\hline $\begin{array}{l}\text { Ten years } O . \\
\text { suave+glycerine }\end{array}$ & 50 & 250 & 21 & 91.4 & 0.423 & $4.0(2.12-5.5)$ \\
\hline Glycerine (Control) & 50 & 250 & 244 & & & \\
\hline Fresh $O$ & 50 & 250 & 28 & 88.7 & 0.427 & $3.5(2.8-4.5)$ \\
\hline $\begin{array}{l}\text { suave+glycerine } \\
\text { Glycerine }\end{array}$ & 50 & 250 & 247 & & & \\
\hline DEET+glycerine & 50 & 250 & 18 & 92.6 & & \\
\hline Glycerine & 50 & 250 & 243 & & & \\
\hline $\begin{array}{l}\text { Ten years } O \text {. } \\
\text { suave+liquid paraffin }\end{array}$ & 100 & 500 & 36 & 92.8 & 0.423 & $1.13(0.9-1.92)$ \\
\hline Liquid paraffin & 100 & 500 & 497 & & & \\
\hline $\begin{array}{l}\text { Fresh } O . \text { suave+liquid } \\
\text { paraffin }\end{array}$ & 100 & 500 & 43 & 91.2 & 0.412 & $1.6(1.1-2.2)$ \\
\hline Liquid paraffin & 100 & 500 & 489 & & & \\
\hline DEET+liquid paraffin & 100 & 500 & 16 & 96.8 & & \\
\hline Liquid paraffin & 100 & 500 & 494 & & & \\
\hline
\end{tabular}


Findings from this study indicate that both fresh and ten years old essential oils provide similar protection efficiency against $A n$. gambiae mosquitoes. Moreover, no difference in protection was observed between 10-years old and freshly prepared essential oils of $O$. suave. The protection efficacies of $O$. suave and DEET were similar. In this study the increase of mosquitoes in a cage from 50 to 100 did not change the feeding inhibition provided by the essential oils indicating that the inhibition is likely to be density-independent. Studies elsewhere have already shown similar protective efficiency of other plants when compared to DEET (Omolo et al., 2004, Odalo et al., 2005).

The longevity of the extracts from $O$. suave, a plant which are found abundantly in majority of rural areas of Tanzania (Chogo \& Crank, 1981) and other part of Africa (Hassanali et al., 1990; Pålsson \& Jaenson, 1999) is an indication that the harvested plant leaves can be stored for quite a long period before oil is extracted and used to prepare repellents. The results of this study have given the highlights of the great possibility of using plant extracts for protection against haematophagus insects when properly formulated and stored. The use of repellent compound is likely to be a complementary intervention when used before someone retires and sleep under a mosquito net.

\section{Acknowledgements}

We would like to thank all who volunteered for the cage feeding. Edward Stephen, Michael A. Mboya; Asteria Maggebo and Sebastian Massawe are highly thanked for attending mosquitoes during experiments. This study was funded by a grant from the Belgium Technical Cooperation offered to Eliningaya Kweka.

Received 27 October 2008

Revised 23 February 2009

Accepted 24 February 2009

\section{References}

Chogo, J.B.A. \& Crank, G. (1981) Chemical composition and biological activity of the Tanzania plant Ocimum suave. Journal of Natural products 44, 308-309.

Hassanali, A., Lwande, W., Ole-sitayo, N., Moreka, L., Nokoe, S. \& Chapya, A. (1990) Weevil repellent constituents of Ocimum suave leaves and Eugenia caryophyllata cloves used as grain protectant in parts of Eastern Africa. Discovery and Innovations 2, 91-95.

Kweka, E.J., Mosha, F., Lowassa, A., Mahande, A., Kitau, J., Matowo, J., Massenga, C., Tenu, F., Feston, F., Lyatuu, E., Mboya, M., Mndeme, R., Chuwa, G. \& Temu, E.A. (2008) Ethnobotanical study of some of mosquito repellent plants in north-eastern Tanzania. Malaria Journal 7, 152.

Mehr, Z.R., Rutledge, L.C., Morales, E.L., Meixsall, V.E. \& Korte, D.W., (1985) Laboratory evaluation of controlled release insect repellent formulations. Journal of American Mosquito Control Association 1,143-147.

Odalo, J.O., Omolo, M.O., Malebo, H., Angira, J., Njeru, P.M., Ndiege, I.O. \& Hassanali, A., (2005) Repellency of essential oils of some plants from the Kenyan coast against Anopheles gambiae. Acta Tropica 95, 210-218.

Omolo, M.O., Okinyo, D., Ndiege, I.O., Lwande, W. \& Hassanali, A. (2004) Repellency of essential oils of some Kenyan plants against Anopheles gambiae. Phytochemistry 65, 2797-2802.

Pålsson, K. \& Jaenson, T.G. (1999) Plant products used as mosquito repellents in Guinea Bissau, West Africa. Acta Tropica 72, 39-52.

Waka, M., Hopkins, R.J. \& Curtis, C. (2004) Ethnobotanical survey and testing of plants traditionally used against haematophagus insects in Eritrea. Journal of Ethnopharmacology 95, 95-101.

Wells, C.D., Mongin, A. \& Bertsch, W. (1993) A study of photosensitive insecticidal volatile compounds in marigold (Tagetes minuta). Journal of High Resolution Chromatography 16, 53-55. 